\title{
Envrionmental impact assessment of urban development plan by vulnerability model application
}

\author{
$I^{*} J$. Nouri and ${ }^{2}$ S. Malmasi \\ ${ }^{1}$ Department of Environmental Health Engineering, School of Public Health and Institute of Health Research Center, \\ Tehran University of Medical Science, Tehran, Iran \\ ${ }^{2}$ Department of Environmental Science, Graduate School of the Environment and Energy, Islamic Azad University, \\ Science and Research Campus, Tehran, Iran
}

\begin{abstract}
Urban development plans have significant potential impacts on affected environment according to the various activities and due to their different construction and operation phases. Establishment and development of the new-established Municipality of Tehran District-22, with about 10,000 hectares area has been planned as the last limit of continuous extension of Great Tehran and as the largest urban city of the country. It is based on the general lay out of Tehran master development plan, ratified in 1970 and 1991. In terms of current facilities, it has been anticipated necessary spaces to establish various activities including residential, commercial and urban services, establishing green spaces, man-made lake and other necessary infrastructures of urban development. Griding method was used in order to determine the environment vulnerability of the development plan of the region. In this method, the studied district has been divided into 1 to 10 square kilometers grids. To improve the accuracy of the study, the grids dimension is smaller than the common size. After griding, the most appropriate layers out of the required layers have been used to determine the vulnerability. These layers are, land slope, geographical aspect, pedology, geology, plant density and ground water vulnerability. The limited codes of each layer have also been defined. Summary of the above-mentioned layers results have been analyzed in the map form 1:50,000 scale by Arc-View software in GIS system in order to determine the specification of impact units. After the determination of limitation, the most prevailing limited code of each grid was selected. The obtained results were transferred to excel program and the final amount of vulnerability were then calculated by using equation $\mathrm{E}=\sum(\mathrm{a}-\mathrm{b}) / 4$. The final vulnerability was substitute by each grid code as a new data and the last map of vulnerability was set. Regarding to this map at the studied region affected by current limitation of environmental condition, the north part of the district especially $\mathrm{A}_{9}, \mathrm{~B}_{10}, \mathrm{~B}_{11}, \mathrm{~B}_{12}, \mathrm{C}_{9}, \mathrm{C}_{11}, \mathrm{C}_{18}, \mathrm{D}_{12}$ and $\mathrm{E}_{14}$ showed the highest amount of vulnerability. According to the final vulnerability map, it is distinguished that the north parts of the district mainly in parts 1 or 2 vulnerability codes have had high vulnerability.
\end{abstract}

Key words: Environmental impact assessment, vulnerability, ground water, drastic model, land use planning

*Corresponding Author, E-mail: nouri@iit.edu

\section{Introduction}

The social-economic transformation of 18 and 19-centurries result in formation of metropolitan and urban areas and currently with extension of development dimension, essential changes in structure and context of cities created. So that discipline of the previous areas was also involved in variations and the city function was affected by development (Keramatollah, 2000). By develoing cities and converting into metropolises, the new cities were designed aimed at social and economic frame decentralization in the civil region of metropolitan. It caused lack of attractiveness to immigrate to large cities and encourage them to leave there to new cities. The new cities are classified into several patterns based on economic activities level including new independent cities and new satellite cities, which have brought about Tehran development and converting it into a metropolis. So that, it is witnessed the creation of new city and town around Tehran with increasing immigration and process of population increasing that it can point to urban development project of Municipality of Tehran District-22. This project is considered as a new continuous city district. The city pattern is established near the mother city to remove the problem of residential repletion. Thus, it is aimed at special settlement and decentralization from the mother city. The new continuous cities are 
always located in adjacent to mother city so that, they gradually blended physically to each other. Municipality of Tehran District 22 with about 10,000 hectares has been planned as the final limit of urban development of the city in terms of master plans, which was ratified in 1970 and 1991 (Urban Planning and Architecture High Council, 1992). This area is bounced on the north to 1800 level of Central Alborz Mountains, on the east to Kan River, on the south to Tehran-Karaj freeway and on the west to low height of Karvan Sara-Sangi. According to predictions of the detailed master plane of Tehran, population of the District-22 has been anticipated over 675, 000 (Nouri and Jozi, 2003). In terms of the current capacities and facilities, the necessary space have been considered to establish various land uses including residential, commercial, services, recreation, the green spaces and man-made lake and other required infrastructures of urban development. For implementation of this plan, respecting environmental considerations and natural limitation and potentials of area has significant importance. In this respect, one of the proper measures to consider environment limitations of the studied district aimed at urban development is determination of current ecological vulnerability of the ecosystem (Makhdoum, 1993; Tang, 2000).

\section{Materials and Methods}

In vulnerability model, the considered ecological factors are mapping and local data are extracted via griding method, and finally a criterion to determine ecological vulnerability are calculated according to environment quality indicator connection, that is provided as a distinguished map called ecological vulnerability map (Canter, 1996; Shariat and Monavvari, 1996).

To determine vulnerability of the area, a griding method has been used. In this method, the considered district is divided into grids with areas of 1 to 10 square kilometers. In the current project, grid dimension has been selected smaller than common size in order to increase accuracy of the study. Griding and representation of defined codes in the studied district are shown in Figure 1.

After griding the studied district, the most appropriate layers out of all provided layers have been used to determine the vulnerability. These layers are land slope, geographical aspects, geology, pedology, plant density and ground water vunerability map. In order to providing the plant density, climate method has been used (Moghaddam, 1998) and ground water vulnerability is provided by using drastic model. Summary of the above-mentioned layer results have been analyzed in the form of 1:50,000 maps via Arc-View software in GIS system to determine specification of the impacted units (Rupert, 2001; Rosen, 2001).

After extracting the prevailing categories in each unit, limitation code of each impact unit was defined so that the closer to threshold rate, the more vulnerability or ecological sensitively is. The extent of the gained numbers has been classified into four categories regarding to the sum of the limited codes calculated from maps to estimate vulnerability of all grids using the following formula (Mansouri, 1998):

$\mathrm{E}=\sum(\mathrm{a}-\mathrm{b}) / 4$

$\mathrm{E}=$ number of deduction in each level $\mathrm{a}=$ the highest number of vulnerability $\mathrm{b}=$ the lowest number of vulnerability $\sum(a-b)=$ differences of the sum of maximum and minimum of the limited codes Number 4 is representative of 4 levels of vulnerability.

After the determination and ranking of vulnerability over the studied district, the results were overlaid with land use planning map of the district (Nouri and Jozi, 2003), as well as, the urban development project, and the most important impacted zone of the project were defined (Table 1).

Table 1: Extent and degree of ecological vulnerability

\begin{tabular}{|ccc|}
\hline $\begin{array}{c}\text { Vulnerability } \\
\text { amount }\end{array}$ & $\begin{array}{c}\text { Vulnerability } \\
\text { degree }\end{array}$ & $\begin{array}{c}\text { Vulnerability } \\
\text { extent }\end{array}$ \\
\hline Resistant & 4 & $9.5-12$ \\
\hline $\begin{array}{c}\text { Semi- } \\
\text { sensitive }\end{array}$ & 3 & $12.25-15.5$ \\
\hline Sensitive & 2 & $15.5-18.75$ \\
\hline Vulnerable & 1 & $18.75-22$ \\
\hline
\end{tabular}

\section{Results}

According to the accomplished studies, specification of different layers of environmental factors in the studied district which was used for vulnerability calculates with regarding to the defined limited codes of each unit, are known as follow:

\section{Geology}

Current geology formation in the area including $\mathrm{PL}-\mathrm{Q}^{\mathrm{a}}$. $\mathrm{Q}_{\mathrm{f}} \cdot \mathrm{Q}_{2}^{\mathrm{t}} \cdot \mathrm{Q}_{1}^{\mathrm{t}}$ is sensitive to erosion, but the sensitivity level is different in each geological formation. 
Table 2: Coding method of geology layers

\begin{tabular}{|cccc|}
\hline Limitation code & Code & Structure name & Levels \\
\hline 4 & 1 & Young terraces- river alluvial & $\mathrm{Q}^{\mathrm{al}} \cdot \mathrm{Q}^{\mathrm{t}}{ }_{2}$ \\
\hline 3 & 2 & Alluvial cone & $\mathrm{Qf}^{\mathrm{t}}$ \\
\hline 2 & 3 & Old terraces & $\mathrm{Q}^{\mathrm{t}}$ \\
\hline 1 & 4 & Pliocene- quaternary & PL-Q \\
\hline
\end{tabular}

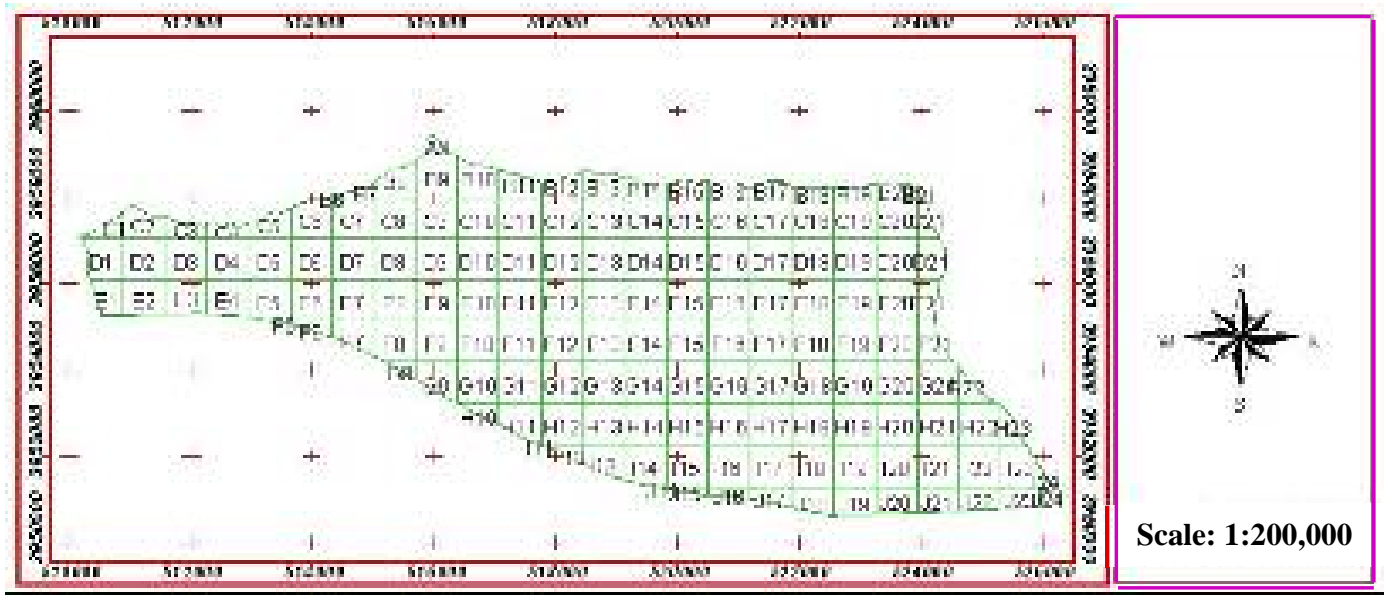

Figure 1: Griding and representation of defined codes in the studied district

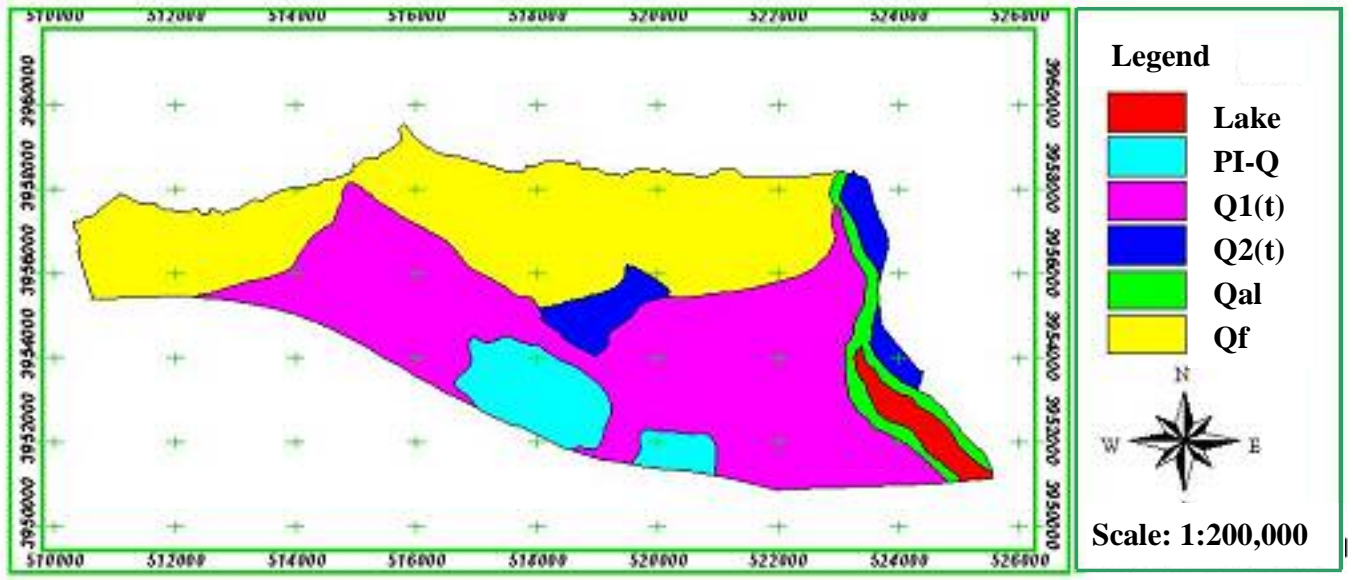

Figure 2: Geology of the studied district

These characteristics are used as criteria for determination of limitation code (Table 2). Geology of the studied district is shown in Figure 2.

\section{Pedology}

Soil of the studied district consists of semideep and deep soils, varied from 5 to 25 percent of gravel. The soil structure of the region is also different from medium to heavy composition. Moreover, soil of the district has been classified on the basis of sensitivity to erosion. It should be mentioned that the most sensitive earth has high limitation, so it has the highest limitation code (Table 3 ).

\section{Land slope}

In order to the slope classification in the studied district, different classes could be 
considered but appropriate classification had been considered in five categories according to urban development plan of Municipality of Districk 22 (Table 4). The land slope map of studied district is shown in Figure 3.

\section{Geographical aspect}

In order to calssify geographical aspect in the studied district, five main aspect have been considerd as defined in the Table 5, among them level $\mathrm{S}$ is the most prevailing direction in the district. The district geopraphical aspects density is given in Figure 4.

\section{Plants density}

Climax method has been used to determine the plant density accumulation. In this classification, vegetation is divided in to 4 categories A, B, C and D based on the values presented in Table 6. Since a part of the studied district allocated to artificial planting, it is considered in classification of vegetation and calculation of limitation.

Table 3: Coding method of soil levels of the studied district

\begin{tabular}{|lcc|}
\hline Earth texture & Code & Limited code \\
\hline Sandy loam & 1 & 5 \\
\hline Loam & 2 & 4 \\
\hline Clay loam- loam & 3 & 3 \\
\hline Loam sandy loam & 4 & 2 \\
\hline Clay loam & 5 & 1 \\
\hline
\end{tabular}

Table 4: Coding method of land slope classification

\begin{tabular}{|ccc|}
\hline Levels & Code & Limitation \\
\hline $0-5$ & 1 & 1 \\
\hline $5-8$ & 2 & 2 \\
\hline $8-15$ & 3 & 3 \\
\hline $15-30$ & 4 & 4 \\
\hline+30 & 5 & 5 \\
\hline
\end{tabular}

Table 5: Coding method of aspect classification

\begin{tabular}{|ccc|}
\hline Aspect & Level & Limitation \\
\hline P & 1 & 1 \\
\hline N & 2 & 2 \\
\hline E & 3 & 2 \\
\hline S & 4 & 3 \\
\hline W & 5 & 3 \\
\hline
\end{tabular}

Table 6: Coding method of vegetation classification

\begin{tabular}{|ccc|}
\hline Levels & Degree (percent) & Limited Code \\
\hline A & $75-100$ & 4 \\
\hline B & $50-75$ & 3 \\
\hline C & $25-50$ & 2 \\
\hline D & $0-25$ & 1 \\
\hline
\end{tabular}




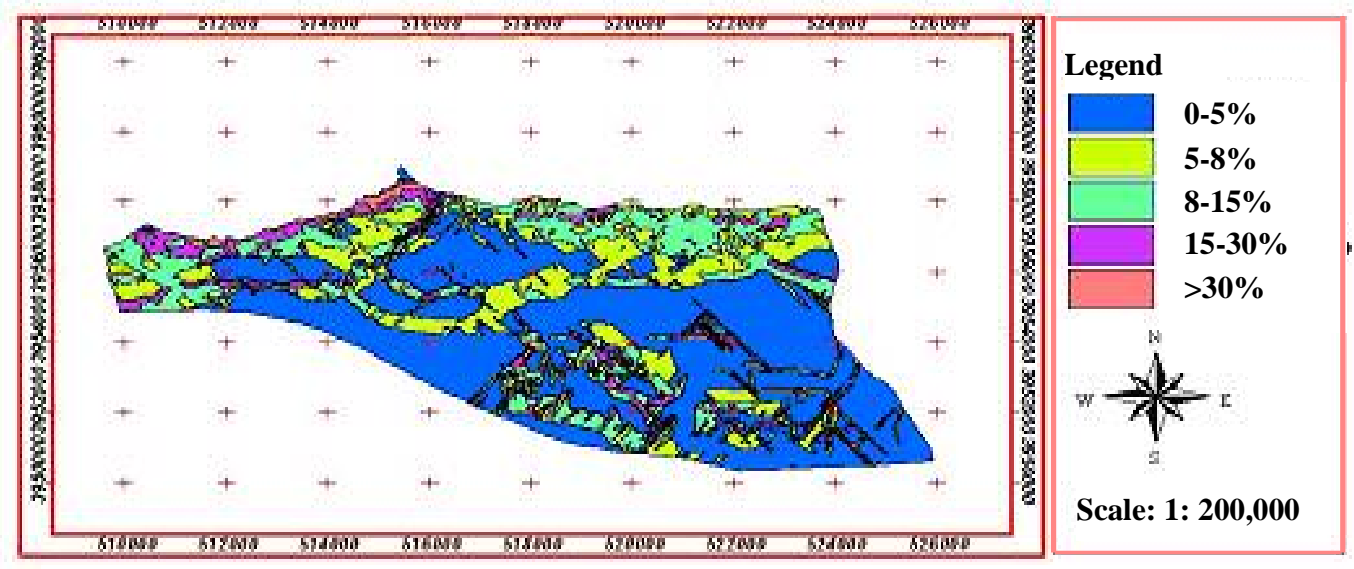

Figure 3: The land slope of the studied district

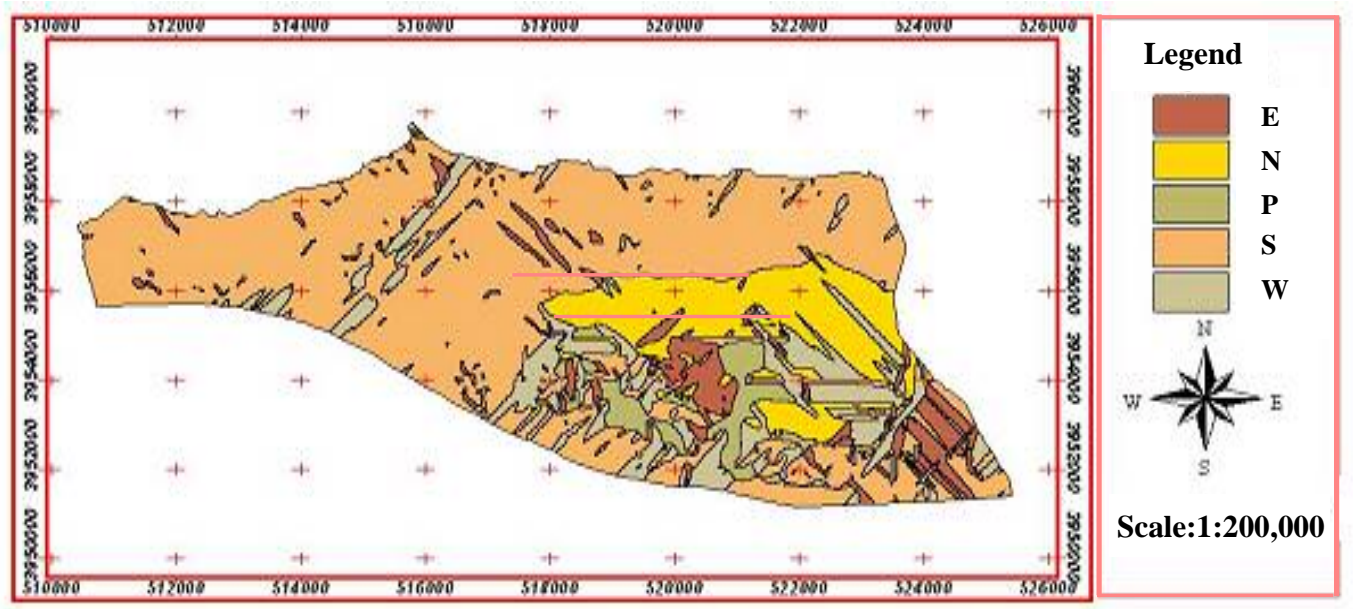

Figure 4: The geographical aspects of studid district

\section{Ground water}

In order to determine the vulnerability of groundwater in the studied district, a drastic index model was used. In this model, seven hydro geological factors which are impressive

to pollution potential of ground waters have been considered including: depth to groundwater (D), net recharg (R), aquifer media (A), soil media (S), topography (T), impact of the vadosezone (I), hydraulic conductivity (C). After weighing and setting evaluation coefficients of the above-mentioned factors in the studied district, the vulnerability map of ground waters was made via an equation to determine the drastic index. The ground water vulnerability map was then classified by limitation code and the outputs used as an information layer for calculation of final environmental vulnerability of the studied district. Vulnerability of ground water resources in district is shown in Figure 5.

After defining limitation codes, the most prevailing code in each grid for all the studied factors were selected via Arc-View software. The obtained results were then transferred in software excel and the amount of the final environmental vulnerability have been calculated by $\mathrm{E}=\sum(\mathrm{a}-\mathrm{b}) / 4$. (The related results of some of the grids are presented in Table 7). The final environmental vulnerability as a new data was substituted each grid code and the final vulnerability map was setup. 
The final environmental vulnerability of the study is given in Figure 6.

\section{Discussion and Conclusion}

Regarding to the final environmental vulnerability in the studied district which has been based on affected by current limitations in environmental condition, the north part of the district, especially $\mathrm{A}_{9}, \mathrm{~B}_{10}, \mathrm{~B}_{11}, \mathrm{~B}_{12}, \mathrm{C}_{9}$, $\mathrm{C}_{11}, \mathrm{C}_{18}, \mathrm{D}_{12}$ and $\mathrm{E}_{14}$ codes located in less developed region have the most vulnerability.
Also, according to vulnerability map, it is defined that the north part of the district is mainly comprised vulnerability degree of one or two and they have high vulnerability for the proposed in the urban development master plan. While, south parts of the studied district have vulnerability degree three. As it is presented in Table 8 , about 81 percent of the studied district has taken sensitive and semisensitive vulnerability, while; only 16 percent has been placed as vulnerable.

Table 7: Results of the limited code and the final vulnerability grade calculation Separated by each grid unit in some part of studied district

\begin{tabular}{|llllllllllllllll|}
\hline & & & & & & & & & & \\
\hline
\end{tabular}

Table 8: Areas allocated to vulnerability level in the studied district

\begin{tabular}{|ccc|}
\hline Vulnerability degree & Area (square meter) & Area (percent) \\
\hline 1 & 9149962.84 & 16 \\
\hline 2 & 24916921.05 & 43 \\
\hline 3 & 22285822.23 & 38 \\
\hline 4 & 1916893.88 & 3 \\
\hline
\end{tabular}




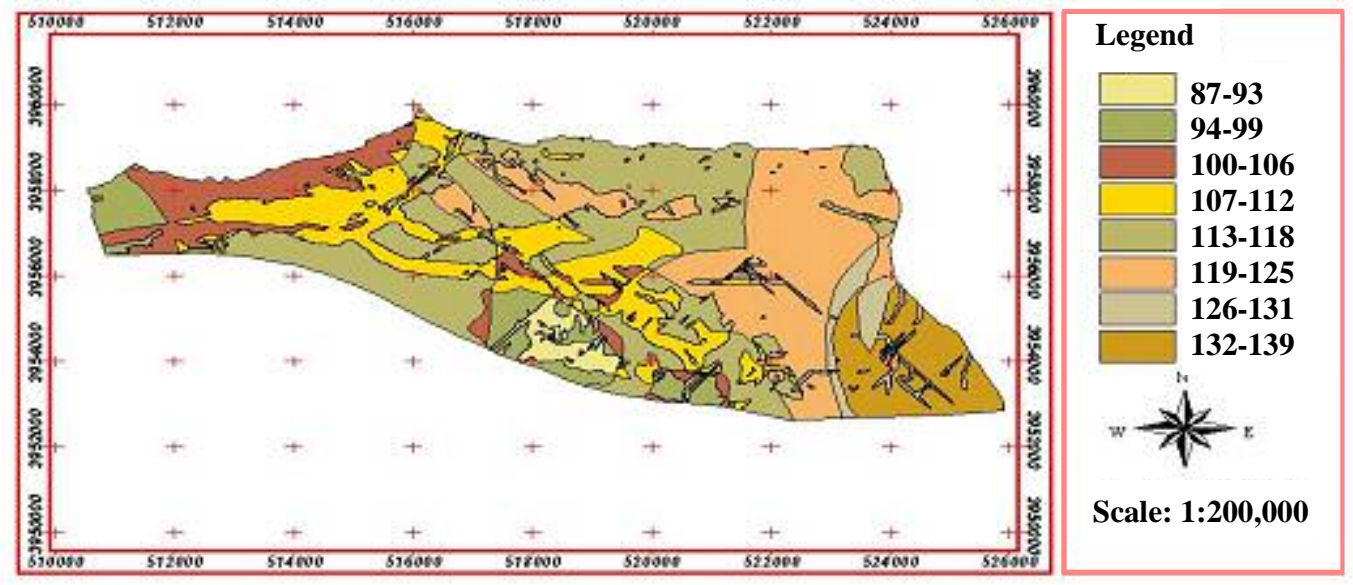

Figure 5: Vulnerability of ground water resources in the studied district

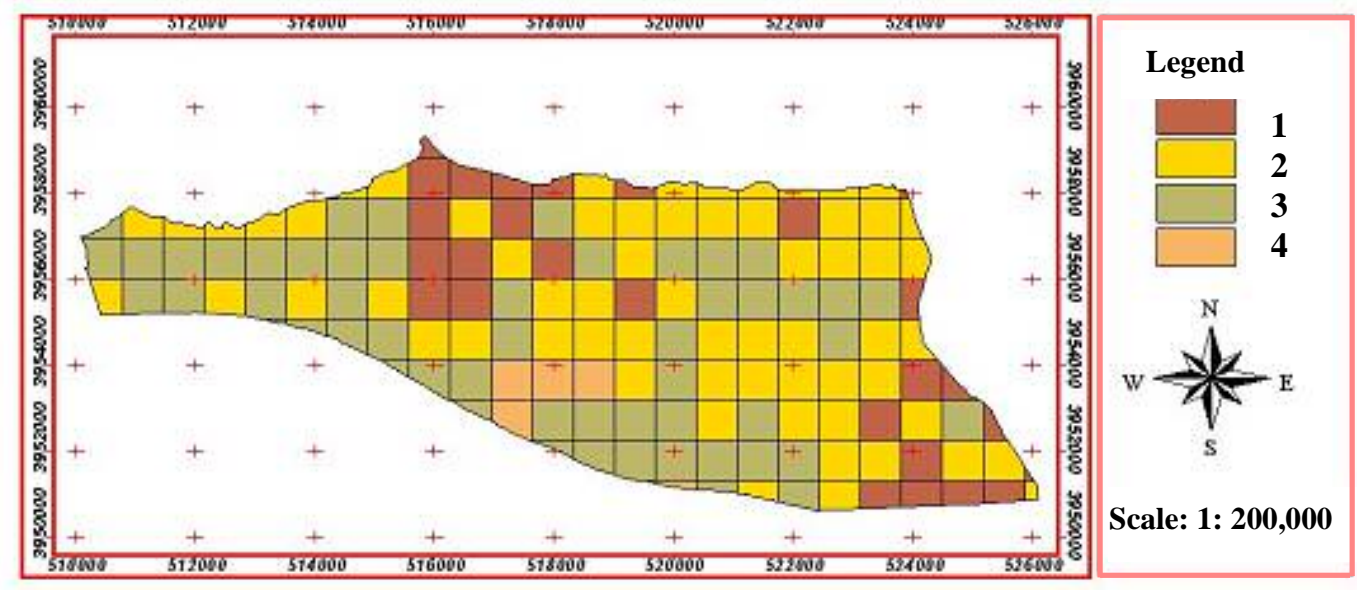

Figure 6: The final environmental vulnerability of the studied district

Figure 7 shows the comparison shares of the vulnerability levels in the studied district. In the other hand, the final vulnerability map can be used to accurate an accuracy in land use planning process in the studied district (Figure 8). In this respect, after compiling the defined codes and overlaying on the urban development extent as specified in the future development map resulted in accuracy in urban development plan of the studied district. Although, this extent concerning environmental factor has more potential to urban development than other defined areas in the zone, overlaying vulnerability layer on this extent represents the limitation including nearly high limitation in the north parts, as well as in the other extents, which have been identified by code 1 of vulnerability. Besides in order to utilize, the development plan map (as a master plan) overlaid and compiled (Figure 9). As considered in this map, some parts of the studied district are not compatible with environmental limitation of the district. In blocks $\mathrm{C}_{18}, \mathrm{E}_{9}, \mathrm{E}_{10}$, despite of the high vulnerability with limitation code 1 , land uses such as residential with high density, commercial administrative centers have been considered based on the master plan. Thus, regarding to the defined limitation code and vulnerability map, it is suggested that settlement land uses with high impact potential like residential land use with high accumulation, highway construction, parking and industrial activities should be avoided and new land uses or replacing suggested land uses of the master plan with their applications that have less potential to destroy like green spaces development, demolished activities and/ or converting to the protected area which should be accomplished. Suggested land uses of the master plan, which have high potential of impacts, ought to be replaced with new less impact activities such as green spaces and lowdensity activities. 


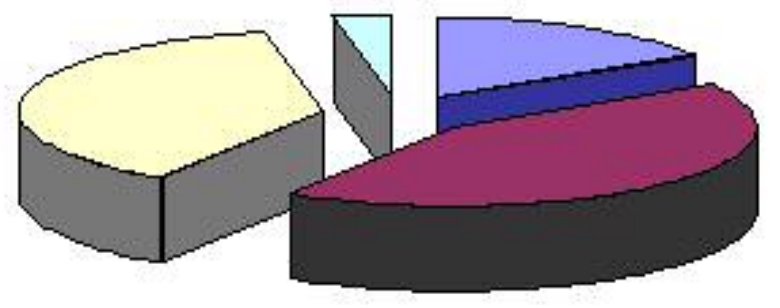

\begin{tabular}{|l|}
\hline$\square$ Vulnerability \\
$\square$ Sensitive \\
$\square$ Semi-Sensitive \\
$\square$ Resistant \\
\hline
\end{tabular}

Figure 7: Comparison the share of vulnerability levels in the studied district

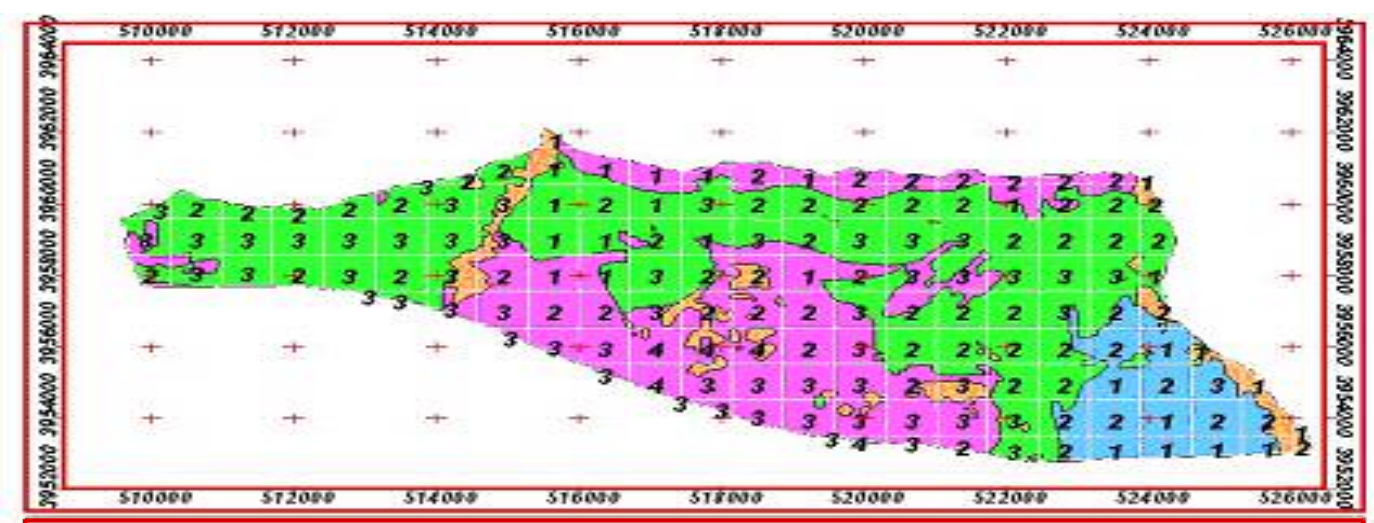

Legend

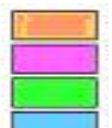

Environment conservation zone

Extensive recreation zone

Urban development zone

Intensive recreation zone

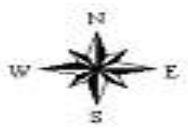

Scale:1:200,000

Figure 8: The accuracy of the land use planning process in the studied district

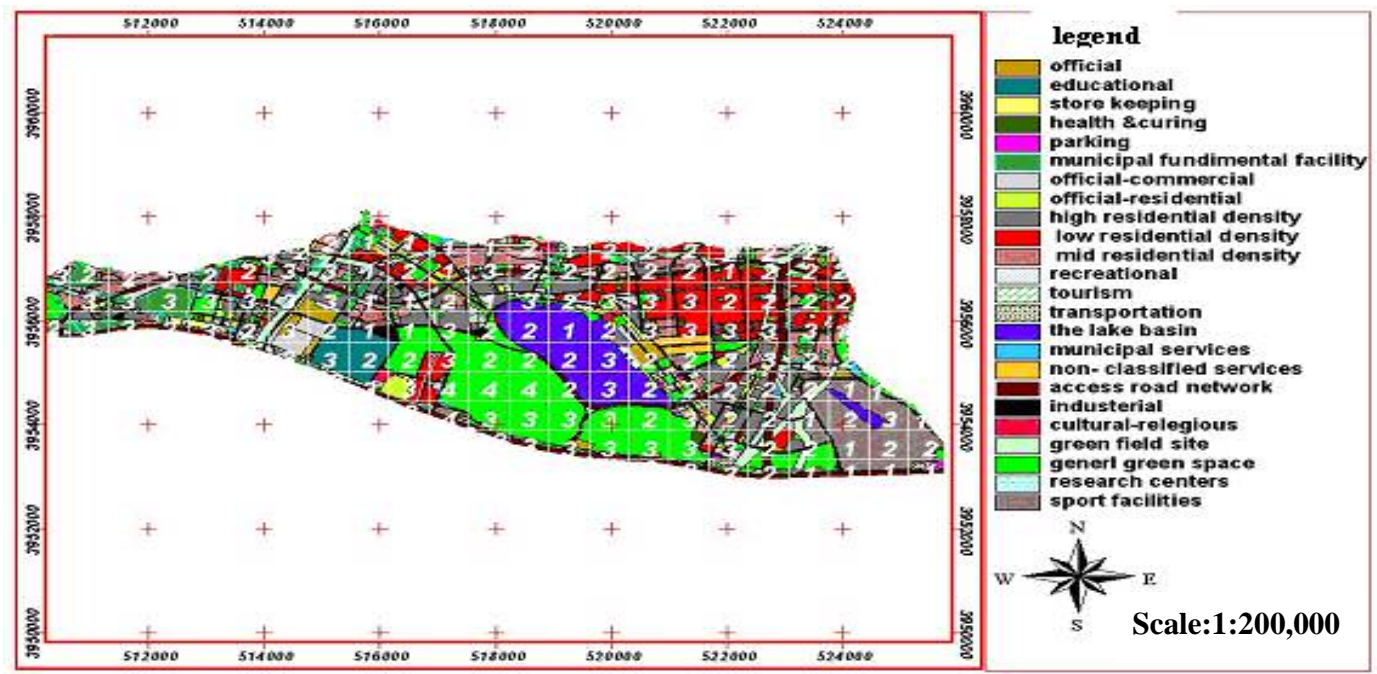

Figure 9: Overlying of vulnerablity layer and the development plan in the studied district 


\section{References}

Canter L.W., Environmental impact assessment. Mc Graw Hill, 1996

Keramatollah, Z., New Towns Planning, SAMT Publication, Tehran, 2000

Makhdoum M., Fundamental of land use planning, Tehran University Publication, 1993

Mansouri, S. M., Study of the environmental impact assessment of Hormozgan province degradation model application. M. S. dissertation, Department of Environmental Science, School of the Natural Resources and Marin Sciences, Tarbiat Moddarres University, 1998

Moghaddam M., Rang management, Tehran university publication, 1998

Nouri, J., A. Jozi, Evaluation of ecological capability of west and northwest of Tehran for ultimate urban development, Asian Network Science Information, Pakistan Journal of biological Sciences, 6 (12):988-993, 2003
Rosen, L., A study of the drastic methodology with emphasis on Swedish condition, Ground Water, 3 (2), 1999

Rupert M.G, Calibration of the drastic ground water vulnerability mapping method, ground water, 39(4), 2001

Shariat M., M. Monavvari Introduction on Environmental Impact Assessment, Department of the Environment, Iran, 1996

Tang W., Chinese urban planning: an assessment of the planning theory literature, Journal of Planning Literature 14:52 61, 2000

Urban Planning and Architecture High Council, Summary of Tehran Master Plan, Ministry of Housing and Urban Development, Islamic Republic of Iran, 1992 
